\title{
Leadership in Plastic Surgery Today
}

\author{
Arturo Prado • Francisco Parada
}

Published online: 8 April 2010

(c) Springer Science+Business Media, LLC and International Society of Aesthetic Plastic Surgery 2010

\begin{abstract}
This article was developed after the authors heard young plastic surgeons of their unit ask what attribute makes people want to follow a leader. What people most seek to find in a leader has been constant over time and shared in different countries, genders, and age groups. These qualities include honesty, a forward-looking perspective, inspiration, and competence (Kouzes and Posner, Clin Lab Manage Rev 8:340, 1994). However, the residents and fellows thought differently and told the authors how "they" wanted to be seen when they became leaders. They wanted to viewed as shifting engines pulling forward teams of plastic surgery as hard as possible, leaving space for followers to develop and grow. They also wanted to be seen as having impeccable behavior related to the assumption of obligations, and finally as having the "most" informal authority possible, an authority that is not negotiable because it is given by peers to the leader due to personal qualities and actions. Obtaining formal authority at a very young age is fine, but if a surgeon's associates have not given him or her informal authority, the surgeon is only the "boss" and not the leader of the group. Informal authority is constructed over a time line and given by others to the leader because of what he or she has in values and personal attitudes and because of what the leader has done and can go on doing with sustained credibility and competency. Therefore, it is the authors' opinion that the exercise of leadership in plastic surgery is supported by
\end{abstract}

\footnotetext{
A. Prado $(\bowtie) \cdot$ F. Parada

Division of Plastic Surgery, School of Medicine, University of

Chile, Manquehue Norte 1707 Suite 210, Vitacura, Area

Metropolitana, Santiago, Chile

e-mail: pradoplast@yahoo.com; arturoaprd@aol.com

F. Parada

e-mail: fcoparada@yahoo.com
}

informal authority and that the leader of leaders will be the one who has the most of this attribute that never is given formally.

Keywords Leadership · Ethics ·

New leaders of plastic surgery

This article aims to show our vision of leadership in plastic surgery after listening to the young plastic surgeons of our unit ask what attribute makes people want to follow a leader. We postulated that the current leaders of plastic surgery face different challenges than previous leaders encountered. Leaders today face novel challenges created by new requirements such as a general movement toward increased specialization within the field of plastic surgery as more knowledge is gained in specific areas and procedures become more complex. They also face a changing ethical environment.

Society recognizes attributes of leadership in general [1] (Table 1). However, are these attributes the same as those that define a good leader of plastic surgery and are they also the attributes of a good surgeon or a good person? We hypothesize about different attributes that could make a good leader of plastic surgery.

\section{Leadership Versus Authority}

Authority often is seen as the possession of power based on a formal role, given primarily for political reasons. Leaders may have formal authority, but they rely in large part on informal authority that flows from personal qualities and actions truly recognized by associates or followers. Leaders may be trusted, respected for their expertise, or followed 
Table 1 Kouzes and Posner's suggestions of what people most seek to find in a leader (in descending order)

Honesty

A forward-looking perspective

Inspiration

Competence

because of their ability to persuade, but finally, they have authority as part of an exchange because if they fail to deliver the goods to meet people's expectations, they run the risk of their authority being removed and given to another by those who have formal authority over them.

\section{Ethics}

Ethics can be considered as a number of rules or standards that govern the conduct of a person or the members of a profession. Leaders of plastic surgery clearly understand that ethics have not changed but that the work environment, the expectations of patients, and the legal framework definitely have changed in plastic surgery.

\section{Confidence}

Confidence can be considered as a judgment or an emotion founded on:

1. Credibility sustained in sincerity and genuineness

2. Predictability with support in behavior coincident with the fulfillment of norms

3. Responsibility related to an impeccable assumption of obligations

4. A sense of purpose.

All this could be seen as a project in itself. A leader is the "alma mater," and it is "his project" to appear as a model of conduct for others.

\section{Excellence Displayed in Patient Care, Research, Education, and the Financial Concerns of Plastic Surgery}

The careers of leaders have been designed to avoid decisions made in ignorance. Leadership is a passionate quest to learn and grow continually. Leaders seize the opportunity to take "stretch" assignments that tax their abilities precisely because they are stimulated by the challenge and the opportunity to increase their knowledge base. Curriculum vitae and academic background are important, but they are not enough to make a leader.

\section{Ability to Mobilize Others}

The ability to mobilize others is done primarily through words and deeds, by making a clear distinction between means and purpose and insisting that the aim is not justified by the means. The important attributes in mobilizing others are a disposition to work with partners and not with servants, a quality of never being regarded with fear by associates, and a sincere respect for the surgical skill, competences, and cleverness of coworkers. This type of leader is never authoritarian or dogmatic but finds the essence of leadership in "being" and not in "doing" projects, and in including all of his or her team.

\section{Vision for New Ideas}

Innovation and creativity will nourish evolutional projects, producing growth of the enterprise and benefiting everyone in it. Leaders often are dissatisfied with the "status quo," searching for new ideas and ways of seeing things with an insatiable thirst for learning that tends to make them more contemporary than their bosses and more aware of leading edge technologies and trends [2, 3].

\section{Accessibility}

Leaders have the ability to recognize the importance of consultation with those affected by their decisions before taking action. Taking consultation seriously means treating people affected by a decision with the dignity and respect they are due.

\section{Intuition}

Leaders have a strong ability to analyze and synthesize large amounts of data and make decisions based not only on particular data but also on intuition as well as a sifting, sorting, and selecting of information based not only on its content but also on its source and on thinking in second, third, and fourth orders of consequence, with clarity about goals and constraints.

\section{Ability to Show the Importance of "Life Boats"}

Leaders develop alternative paths, with backup plans in the event a decision proves wrong because they are intellectually honest and have the self-confidence to acknowledge when they do not have the answers. 


\section{Discussion}

The central part of this article was developed after listening and having very productive conversations with young plastic surgeons asking for help and ways to recognize whether they had the potential to become leaders. They told us how "they" wanted to be seen when they became leaders:

1. As shifting engines that pull forward teams of plastic surgery as hard as possible, leaving space for followers to develop and grow

2. As having impeccable behavior related to the assumption of obligations

3. As having "given" formal authority but understanding that informal authority is not negotiable because it is given by peers to the leader due to personal qualities and actions.

Maybe the last point was the most interesting part of this discussion because the current leaders of plastic surgery appear to be younger and specialty trained [4]. However, leadership in plastic surgery is not the same as in "economics," where a CEO can be a very young person. In the "medical-plastic surgery" environment, the need for experience is essential. Leaders can receive formal authority at a very young age, but if their associates have not given them informal authority, they are only the "boss" and not the leader of their group.

To young plastic surgeons seeking to increase informal authority among associates, we recommend the following:

1. Listen carefully because listening is more important than speaking. True listening is hearing and interpreting at the same time. It is not what is being said but what your associates are trying to say to you. Also a leader must make true efforts to cultivate conversations that will mobilize others.

2. Give and receive "feedback."

3. Have a project with a "sense of purpose."

\section{Conclusion}

What it is the attribute that makes people want to follow a leader? We answer that it is "informal authority" given to true leaders by their peers. Informal authority is constructed over a time line. It is given by others to the leader because of his or values and personal attitudes and because of what the leader has done and can go on doing with sustained credibility and, most of all, competency. In summary, it is our opinion that the exercise of leadership in plastic surgery is supported by informal authority and that the leader of leaders will be the one who has the most of this attribute that is never given formally.

\section{References}

1. Kouzes JM, Posner BZ (1994) The credibility factor: credibility is the foundation of leadership. Clin Lab Manage Rev 8:340

2. Prado A, Andrades P (2008) Creativity in plastic surgery. Aesth Plast Surg 32:409-410

3. Prado A, Andrades P (2009) Creativity, innovation, and knowledge should defeat financial crisis in plastic surgery. Plast Reconstr Surg 124:657

4. Addona T, Polcino M, Silver L, Taub PJ (2009) Leadership trends in plastic surgery. Plast Reconstr Surg 123:750 